\title{
Reduction of photosynthetic apparatus plays a key role in survival of the microalga Haematococcus pluvialis (Chlorophyceae) at freezing temperatures
}

\author{
K. CHEKANOV ${ }^{* * *+}$, S. VASILIEVA*, A. SOLOVCHENKO*, and E. LOBAKOVA* \\ Biological Faculty, Lomonosov Moscow State University, 1/12 Leninskie Gory, 119234 Moscow GSP-1, Russia* \\ National Research Nuclear University MEPhi, Centre for Humanities Research and Technology, Moscow, Russia**
}

\begin{abstract}
The microalga Haematococcus pluvialis is a biotechnologically important microorganism producing a ketocarotenoid astaxanthin. Haematococcus exists either as metabolically active vegetative cells with a high chlorophyll content or astaxanthin-rich haematocysts (aplanospores). This microalga featuring outstanding tolerance to a wide range of adverse conditions is a highly suitable model for studies of freezing tolerance in phototrophs. The retention of $H$. pluvialis cell viability after freezing-thawing is ascribed to elevated antioxidant enzyme activity and high ketocarotenoid content. However, we report that only haematocysts characterized by a lower photosynthetic activity were resistant to freezingthawing even without cryoprotectant addition. The key factors of haematocyst freezing tolerance were assumed to be a low water content, rigid cell walls, reduction of the membranous structures, photosynthesis downregulation, and low chlorophyll content. Collectively, viability of Haematoccus after freezing-thawing can be improved by forcing the transition of vegetative cells to freeze-tolerant haematocysts before freezing.
\end{abstract}

Additional key words: cold stress; Haematococcys pluvialis; stress tolerance.

\section{Introduction}

Cryopreservation is a widespread method for the maintaining collections of microorganisms (Day and DeVille 1995) including single-celled phototrophs (microalgae). Many culturable cyanobacteria and soil microalgae can be cryopreserved with a relatively high retention of the cell viability whereas freshwater and marine eukaryotic microalgae are more problematic in this regard (Day and DeVille 1995, Day and Brand 2005, Morschett et al. 2016, Saadaoui et al. 2016). Development of cryopreservation protocols for diverse groups of algae is highly topical since it can, in many cases, save the labor, time, and costs of traditional collection maintenance via subculturing of the cells. Accordingly, investigation of the effect of low (freezing) temperatures on the condition of photosynthetic apparatus and its involvement in freezing-thawing tolerance of microalgae is essential for development of the efficient cryopreservation protocols for these organisms.

Existing techniques of microalgae cryopreservation are, as a rule, based on complex species-specific protocols (Morris 1978, Day and DeVille 1995, Day et al. 1997, Day and Brand 2005). Viability of the cells upon freezing and thawing depends on a wide range of factors some of which were extensively studied. Probably the most elucidated factor is the addition of various cryoprotective agents or their mixtures - low-molecular-mass carbohydrates, polyols, dimethyl sulfoxide (DMSO), polymers; their

Received 31 May 2017, accepted 15 November 2017, published as online-first 21 June 2018.

${ }^{+}$Corresponding author; e-mail: chekanov@mail.bio.msu.ru

Abbreviations: CF - chlorophyll fluorescence; Chl - chlorophyll(s); CM - cryoprotectant mixture; DMSO - dimethyl sulfoxide; $\mathrm{DM}$ - dry mass; ETC - electron transport chain; FM - fresh mass; $\mathrm{F}_{\mathrm{m}}$ - maximal CF in the dark-adapted state; $\mathrm{F}_{0}-$ minimal CF in the dark-adapted state; $\mathrm{hC}^{(-)}$- haematocysts of $H$. pluvialis frozen without $\mathrm{CM}$; $\mathrm{hC}^{(+)}$- haematocysts of $H$. pluvialis frozen with $\mathrm{CM}$; ROS - reactive oxygen species; SEM - scanning electron microscopy; TEM - transmission electron microscopy; $\mathrm{vC}^{(-)}$- vegetative cells of $H$. pluvialis frozen without $\mathrm{CM} ; \mathrm{vC}^{(+)}$- vegetative cells of $H$. pluvialis frozen with $\mathrm{CM} ; \mathrm{N}-\mathrm{Q}_{\mathrm{A}}$ turnover number; $\Psi_{0}-$ the probability of electron transport beyond $\mathrm{Q}_{\mathrm{A}} ; \varphi_{\mathrm{P}}-$ maximal PSII photochemical quantum yield in the dark-adapted state; $\varphi_{\mathrm{E} o}-$ the quantum yield of electron transport; $\varphi_{\text {Do }}$ - the quantum yield of energy dissipation.

Acknowledgments: Financial support of the Russian Science Foundation (grant 14-50-00029) is gratefully acknowledged. The electron microscopy part of the work was carried out at the User Facilities Center of M.V. Lomonosov Moscow State University. The dedicated technical assistance of Mr. Alexei Titov is greatly appreciated. 
adequate concentration is essential for retention of the cell viability (Cañavate and Lubian 1994, Day and DeVille 1995, Day et al. 1997, Morschett et al. 2016). Cell encapsulation in calcium alginate also augments viability of the cells (Harding et al. 2008). Freezing and thawing at a precisely controlled rate are widespread cryopreservation procedures including two-step modifications (controlled rate freezing and vitrification, see Morris 1978, Cañavate and Lubian 1994, Bui et al. 2013). Other factors, such as cell density of the sample (Brand and Diller 2004, Piasecki et al. 2009, Bui et al. 2013), preliminary centrifugation (Bui et al. 2013), and ion strength (Cañavate and Lubian 1995), may be also essential. The main problem of the development of cryopreservation procedures is their high species and strain specificity (Cañavate and Lubian 1994, Day et al. 1997, Morschett et al. 2016, Morris 1978). Thus, a lot of routine experimentation is necessary to develop an optimal cryopreservation method for each culture. In view of this, it would be attractive to employ some internal physiological markers of microalgal cell conditions to assess its tolerance to adverse conditions, e.g., freezing. Furthermore, many microalgal species display a high resistance to stressors, so insight into its mechanisms and induction may be instructive for the development of more universal cryopreservation techniques. For example, it was determined that accumulation of triacyl glycerols in the cells of microalgae increases post-thawing viability (Saadaoui et al. 2016). However, as far as we know, the exact mechanism of the protective effect of triacyl glycerol accumulation is unknown.

\section{Materials and methods}

Strain, vegetative growth, and the induction of haematocyst transition: The strain $H$. pluvialis BM1 (IPPAS H-2018) isolated from the White Sea (Chekanov et al. 2014) was used. H. pluvialis biomass for freezingthawing experiments was obtained by cultivation of the microalgae in a glass column photobioreactor under conditions conductive for vegetative cell growth under 5\% $\mathrm{CO}_{2}$ in the air-gas mixture for the culture sparging as described in Chekanov et al. (2017). The transition of the vegetative cells to haematocysts was induced as described in Chekanov et al. (2017) immediately before freezing.

Freezing procedure: A suspension of the vegetative cells from an exponential growth phase or haematocysts $(5 \mathrm{ml}$, $1 \times 10^{6}$ cells $\mathrm{ml}^{-1}$ ) was transferred into $5-\mathrm{ml}$ polypropylene cryotubes (TPP, Switzerland). The culture density of $1 \times$ $10^{6}$ cells ml $^{-1}$ (Brand and Diller 2004, Bui et al. 2013) or lower (Piasecki et al. 2009) are essential for the viability of green microalgae strains after thawing. In order to reduce a supernatant, the cell suspensions were centrifuged (5810R, Eppendorf, Germany) at $965 \times g$ for $5 \mathrm{~min}$ at $25^{\circ} \mathrm{C}$. To study the effect of the cryoprotectant addition, the cryoprotecant mixture $(\mathrm{CM})$ containing DMSO and glycerol $[2 \%$ and $5 \%$ of culture dry mass (DM),
The microalga Haematococcus pluvialis (Chlorophyceae) featuring outstanding tolerance to a wide range of adverse conditions, such as low temperatures and high light (Boussiba 2000, Han et al. 2013, Klochkova et al. 2013, Solovchenko 2015), is a suitable model for studies of freezing tolerance in microalgae. However, the mechanisms and role of photosynthetic apparatus in cryotolerance of $H$. pluvialis are poorly understood so far. The retention of $H$. pluvialis cell viability after freezingthawing is ascribed to elevated activity of antioxidant systems in and high ketocarotenoid content of the cell (Fleck et al. 2003), although the corresponding experimental evidence is scarce.

Peculiar to $H$. pluvialis is the transformation of its green vegetative cells to red aplanospores (haematocysts) characterized by a high content of the ketocarotenoid astaxanthin and a very low photosynthetic activity (Boussiba 2000, Chekanov et al. 2016, Han et al. 2013, Solovchenko 2015). In the present study, we evaluated the condition of photosynthetic apparatus in frozen-thawed cells of $H$. pluvialis BM1 (IPPAS H-2018) cells before and after the induction of their transition to haematocysts. We focused predominantly on the effect of physiological state of the cell (either vegetative cell or haematocyst), which seems to be more important for the retention of post-thawing viability. At the same time, we did not try to optimize the cryopreservation procedure adopting one that was previously described. Towards this end, we compared pigment accumulation, ultrastructure and photosynthetic performance of the cells before and after freezing and thawing.

respectively] was added to the samples before freezing (Dr. Tatiana Fedorenko, personal communication; Bodas 1995, Day and Brandt 2005). DM was determined gravimetrically (Pal et al. 2011). The cells were resuspended in the CM. Some samples were frozen without CM. The cryotubes were frozen at $-80^{\circ} \mathrm{C}$ and stored for one month at those conditions in an ultra-low temperature freezer C585-86 (New Brunswick Scientific, USA). In total, four experimental treatments were studied: vegetative cells and haematocysts of $H$. pluvialis frozen with or without CM.

\begin{tabular}{lll}
\hline Designation & CM addition & Cell type \\
\hline $\mathrm{vC}^{(-)}$ & - & Vegetative cells \\
$\mathrm{vC}^{(+)}$ & + & Vegetative cells \\
$\mathrm{hC}^{(-)}$ & - & Haematocysts \\
$\mathrm{hC}^{(+)}$ & + & Haematocysts \\
\hline
\end{tabular}

The cells were thawed at room temperature for $15 \mathrm{~min}$. To reduce the risk of photodamage (Bui et al. 2013), the thawing was carried out in the dark. The samples containing CM were twice washed by the medium BG-11 (Stanier et al. 1971) in the dark. The thawed samples were 
incubated in 100-ml glass conical flasks in $50 \mathrm{ml}$ of the same medium in an Innova $44 R$ shaker (Eppendorf, Germany) at $120 \mathrm{rpm}, 25^{\circ} \mathrm{C}$, and continuous illumination [PAR of $20 \mu \mathrm{mol}$ (quantum) $\mathrm{m}^{-2} \mathrm{~s}^{-1}$ as measured by a $\mathrm{LiCor}$ 850 quantum sensor ( $\mathrm{LiCor}$, USA)] by cold-white LED for $7 \mathrm{~d}$. To estimate the ability of the thawed H. pluvialis to accumulate astaxanthin, the cells were taken after $7 \mathrm{~d}$ of cultivation in the flasks. They were cultivated in photobioreactor under the vegetative growth conditions (Chekanov et al. 2017) to the density of $1.0 \mathrm{mg}$ (cell DM) $\mathrm{ml}^{-1}$ and then exposed to a high light intensity and deprived of nitrogen to induce astaxanthin accumulation as described in Chekanov et al. (2017).

Cell viability assay: The cells were studied under bright field and fluorescence mode under Eclipse 90i (Nikon, Japan) motorized photomicroscope. The cell viability was estimated via the presence of the red chlorophyll (Chl) autofluorescence (Pouneva 1997). The cells lacking green $\mathrm{Chl}$ pigmentation and hence the red $\mathrm{Chl}$ fluorescence $(\mathrm{CF})$ were considered as dead.

Electron microscopy: The cells of $H$. pluvialis were sampled for the electron microscopy observations immediately after thawing. Vegetative cells from the exponential growth phase and haematocysts, which were not frozen, were taken as a control. The samples for transmission electron microscopy (TEM) and scanning electron microscopy (SEM) were prepared according to Chekanov et al. (2014). Ultrathin sections were prepared using an ultramicrotome LKB 4800 (Broma, Sweeden). TEM analysis was performed on the electron microscope Hitachi HU-11F (Hitachi Ltd., Japan). For SEM analysis, the samples were dried at $\mathrm{CO}_{2}$ critical point in $H C P-2$ dryer (Hitachi, Japan) and coated by $\mathrm{Pd}$ in an IB Ion Coater (Eiko, Japan).

Chl assay and water content determination: $\mathrm{Chl} a$ and Chl $b$ contents in the cells of $H$. pluvialis were assayed spectrophotometrically in DMSO extracts as described previously (Chekanov and Solovchenko 2015) using

\section{Results}

Cells viability: There were no viable cells after $7 \mathrm{~d}$ of postthaw cultivation in the $\mathrm{vC}^{(-)}$sample (Fig. $1 A$ ). The viability level was approximately equal for the $\mathrm{vC}^{(+)}$cells $(50 \pm$ $10 \%)$ and $\mathrm{hC}^{(-)}$cells $(55 \pm 18 \%)$. The highest post-thaw viability level of $86 \pm 14 \%$ was recorded in the $\mathrm{hC}^{(+)}$ sample.

Ultrastructure: As it was revealed by SEM, the vegetative cells of $H$. pluvialis, which were not frozen, possessed a spherical shape, existed as individual cells or formed palmelloid clusters. The cells were 8.0-25.0 $\mu \mathrm{m}$ in diameter (Fig. 2A). The haematocysts were spherical equations reported by Solovchenko et al. (2010).

For determination of the water content in the $H$. pluvialis vegetative cells and haematocysts, the cells were deposited on $G F / F$ glass-fiber filters (Whatman, UK). Extracellular water was removed using $M E ~ 1 C$ vacuum pump (Vacuubrand, Germany). Neglecting the effect of capillarity water mass fraction in the cells was calculated as $(\mathrm{FM}-\mathrm{DM}) / \mathrm{FM} \times 100 \%$, where $\mathrm{FM}$ and $\mathrm{DM}$ are fresh and dry cells mass. In order to consider the amount of water in the filter, the mass difference between wet and dry empty filter was subtracted from the FM.

CF analysis: CF induction curves (Goltsev et al. 2016, Kalaji et al. 2016) of $H$. pluvialis cells were recording using Fluorpen FP100s portable pulse amplitude modulated fluorometer (Photon Systems Instruments, Czech Republic) as described previously (Chekanov et al. 2016) in cell suspension samples with optical density of $0.1-0.5$ at $660 \mathrm{~nm}$ placed in 1-cm quartz cuvette. Blue light emitting diode $(455 \pm 5 \mathrm{~nm})$ was used. The photon flux density of the measuring light and saturation pulses were 5 and 3,000 $\mu \mathrm{mol}$ (quantum) $\mathrm{m}^{-2} \mathrm{~s}^{-1}$, respectively. The cells were dark-adapted for $15 \mathrm{~min}$ before measurements. Maximal PSII photochemical quantum yield of darkadapted cells $\left(\varphi_{\mathrm{Po}}\right)$ was calculated as $\varphi_{\mathrm{Po}}=\left(\mathrm{F}_{\mathrm{m}}-\mathrm{F}_{0}\right) / \mathrm{F}_{\mathrm{m}}$, where $F_{0}$ is the minimal and $F_{m}$ is maximal $C F$ intensity excited in dark-adapted cells during saturation pulse exposition (Goltsev et al. 2016, Kalaji et al. 2016). For more detail analysis of CF transient curves, some additional parameters were calculated in accordance with theory of Strasser et al. (2000): the probability of electron transport $\mathrm{Q}_{\mathrm{A}}\left(\Psi_{0}\right)$, the quantum yield of electron transport $\left(\varphi_{\mathrm{Eo}}\right)$, the quantum yield of energy dissipation $\left(\varphi_{\mathrm{Do}}\right)$, and $\mathrm{Q}_{\mathrm{A}}$ turnover number, see Fig. 1S (supplement available online).

Data analysis: The data were treated using Origin Pro 8.0 software (OriginLab, USA). All measurements were carried out in triplicate. Average values and SD are presented. Statistical significance of the difference was estimated by standard $F$-test $(P=0.95)$.

(10.0-20.0 $\mu \mathrm{m}$ in diameter) with 5.0-12.0 $\mu \mathrm{m}$ dents on their surface (Fig. 2B). Most of the $\mathrm{vC}^{(-)}$cells lacked a spherical shape and possessed numerous perforations and cracks of their surface (Fig. $2 C$ ). The perforations of $\mathrm{vC}^{(-)}$ were quite large (3.0-5.0 $\mu \mathrm{m}$ in diameter; Fig. $2 E)$.

Most of the vegetative cells frozen with CM and thawed appeared relatively undamaged. They retained the spherical shape (as it was typical for these cells before freezing) in contrast to $\mathrm{vC}^{(-)}$. The surface of $\mathrm{vC}^{(+)}$cells often possessed many visible defects although the latter were not as large and deep as in the case of the $\mathrm{vC}^{(-)}$cell (Fig. 2D,F). The shape and structure of the surface 

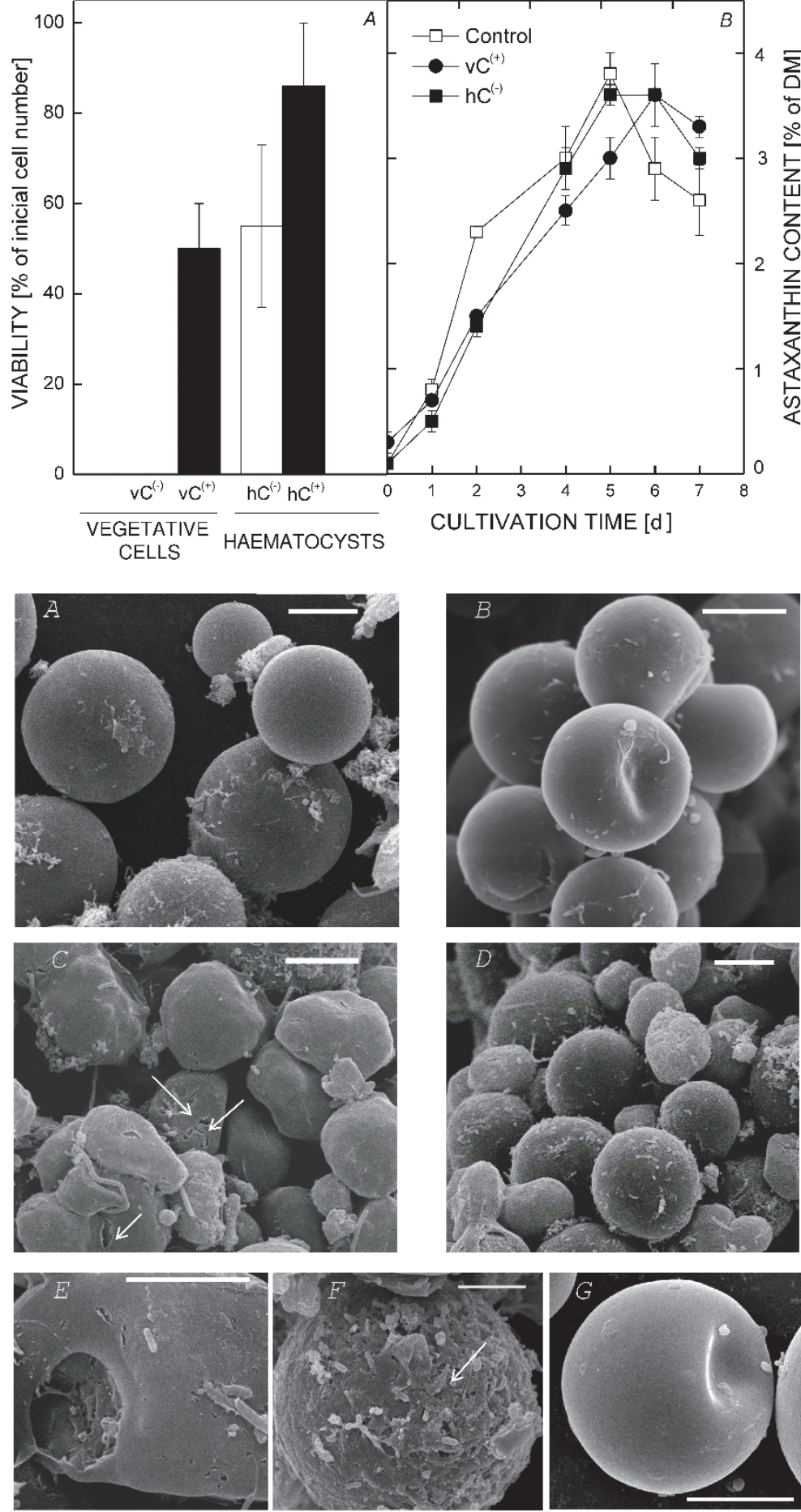

Fig. 1. (A) Viability of haematocysts and vegetative cells of Haematococcus pluvialis BM1 cultivated autotrophically during $7 \mathrm{~d}$ after thawing. Viability was calculated as $\mathrm{n} / \mathrm{n}_{0} \times 100 \%$, where $\mathrm{n}$ and $\mathrm{n}_{0}$ are the cell number at $7 \mathrm{~d}(170 \mathrm{~h})$ and $0 \mathrm{~h}$ of cultivation respectively. $\mathrm{C}^{(+)}, \mathrm{C}^{(-)}$are cells with and without cryoprotectants mixture respectively. (B) Astaxanthin accumulation in $H$. pluvialis cells under inductive conditions. Astaxanthin content was calculated as a percentage of cells dry mass (DM). Average values of three replicates and their SDs are presented in the figures.

Fig. 2. The morphology (SEM images) of Haematococcus pluvialis: $(A)$ nonfreezed vegetative cells (control); $(B)$ nonfreezed haematocysts (control); $(C)$ vegetative cells after the freezing without cryoprotectants; $(D)$ vegetative cells after the freezing with cryoprotectants; $(E)$ the holes in a vegetative cell after the freezing without cryoprotectants; $(F)$ the holes in a vegetative cell after the freezing with cryoprotectants; $(G)$ a haematocyst after the freezing without cryoprotectants. CW - cell wall; OB - oil bodies; $\mathrm{T}$ - thylakoids. Scale bars $10 \mu \mathrm{m}(A-E), 5 \mu \mathrm{m}$ $(F, G)$.

of haematocysts $\left(\mathrm{hC}^{(+)}, \mathrm{hC}^{(-)}\right)$did not differ visually from the control (nonfrozen) H. pluvialis cells (Fig. 2G).

On the ultrathin sections, the vegetative cells possessed the thick cell wall (up to $0.4 \mu \mathrm{m}$ ) and thin $(0.1 \mu \mathrm{m})$ extracellular matrix (Fig. $3 A$ ). The nonfrozen vegetative cells were characterized by well-developed thylakoid system of chloroplast with a high degree of stacking, which occupied most of the cell area on the cross-sections (Fig. 3A). The ultrastructure of the $\mathrm{vC}^{(-)}$cells differed from that of the nonfrozen cells. In the former, cell wall was absent or damaged. The $\mathrm{vC}^{(-)}$cells displayed the signs of thylakoid disorganization (Fig. 3B), e.g., thylakoid membrane fractures (Fig. 3B). Remarkably, cell wall and thylakoid structure of the $\mathrm{vC}^{(+)}$cells was much better preserved (Fig. 3C).

The $\mathrm{hC}^{(-)}$cells were characterized by the presence of cytoplasmic oil globules of $0.4-2.5 \mu \mathrm{m}$ in diameter (Fig. $3 D$ ). The thylakoid system of the photosynthetic 

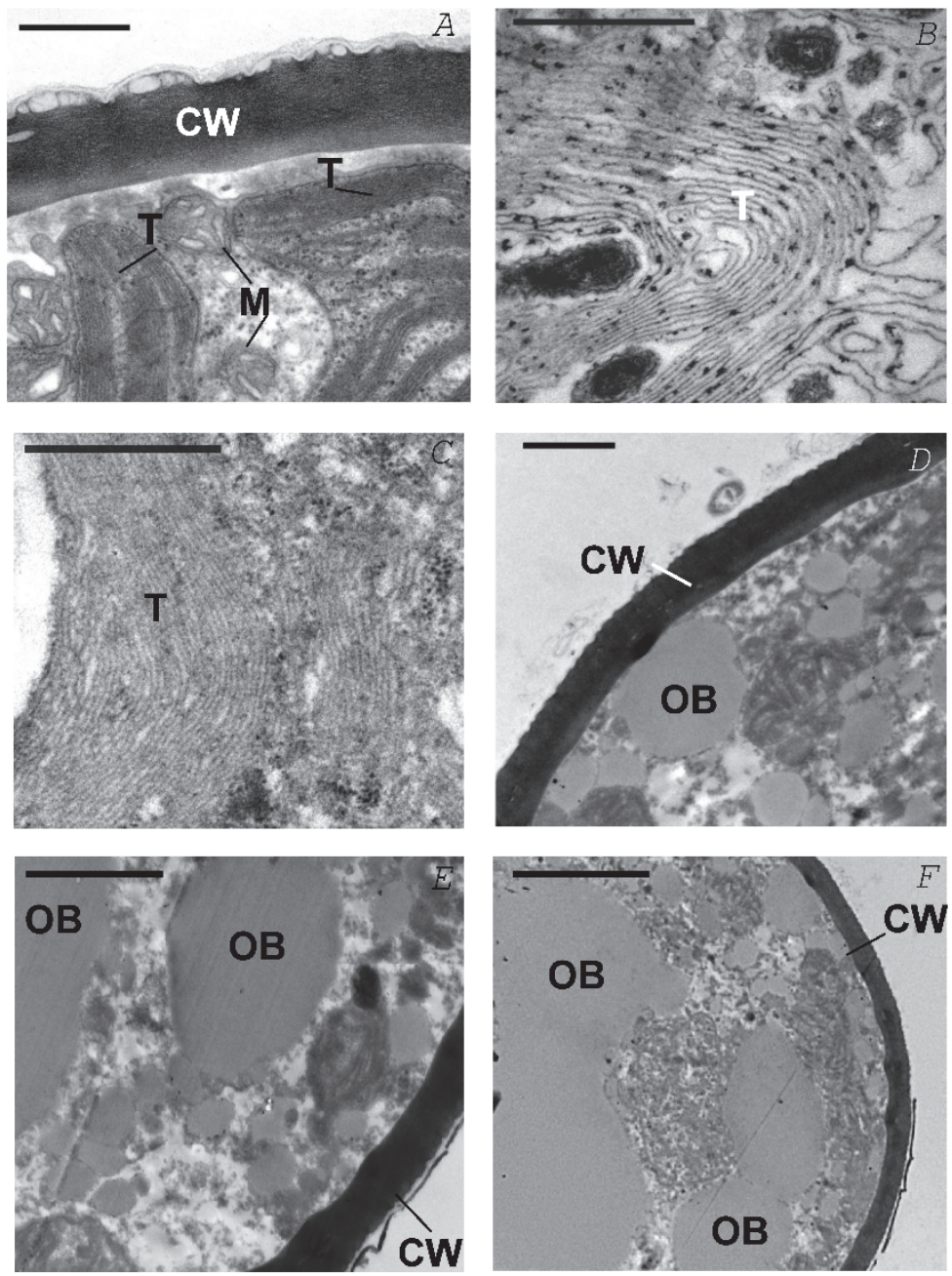

Fig. 3. The ultrastructure (TEM images) of Haematococcus pluvialis: $(A)$ the ultrathin section of the nonfreezed vegetative cell's periphery (control); $(B)$ the swelling of thylakoids in a vegetative cell after the freezing without cryoprotectants; $(C)$ a thylakoids structure in a vegetative cell after the freezing with cryoprotectants; $(D)$ the ultrathin section of the haematocyst's periphery after the freezing without cryoprotectants, $(E)$ haematocyst freezed with cryoprotectants mixture, and $(F)$ nonfreezed haematocysts (control). CW - cell wall; $\mathrm{OB}$ - oil bodies; $\mathrm{T}$ - thylakoids; $\mathrm{M}-$ mitochondrion. Scale bars $0.4 \mu \mathrm{m}(A), 2 \mu \mathrm{m}(B), 1 \mu \mathrm{m}(C, D), 4 \mu \mathrm{m}(E, F)$. apparatus was less developed in the haematocysts (Fig. $3 F$ ) in comparison to the vegetative cells (Fig. 3A). The thickness of the cell wall was in the range of 1.0-1.5 $\mu \mathrm{m}$. Neither hC ${ }^{(-)}$(Fig. 3D) nor $\mathrm{hC}^{(+)}$(Fig. 3E) haematocysts displayed destructive changes of the cell wall and intracellular membranous structures after freezing and thawing. Thus, freezing did not affected significantly the ultrastructure of the haematocysts as compared to the nonfrozen cells (Fig. 3D,E,F).

Pigment and water content: The water content in the H. pluvialis vegetative cells and haematocysts before the freezing procedure was $71.1 \pm 17.0 \%$ and $26.0 \pm 13.3 \%$, respectively.

The Chl content in the $\mathrm{vC}^{(-)}$and $\mathrm{vC}^{(+)}$cell suspensions immediately after thawing was $12.0 \pm 0.5 \mathrm{mg} \mathrm{l}^{-1}$ and $7.2 \pm$ $0.1 \mathrm{mg} \mathrm{l}^{-1}$, respectively, (Fig. $4 A$ ) which was lower than the Chl content of nonfrozen vegetative cells. It corresponded to $12.0 \pm 0.5 \mathrm{pg}$ per cell and $7.2 \pm 0.1 \mathrm{pg}$ per cell, respectively (Fig. 4B). During the post-thaw cultivation, the $\mathrm{Chl}$ content in the $\mathrm{vC}^{(+)}$cells increased gradually and, after $7 \mathrm{~d}$ reached $11.5 \pm 0.1 \mathrm{mg} \mathrm{l}^{-1}$ (Fig. $4 A$ ) or $19.2 \pm$ $0.4 \mathrm{pg}$ per cell (Fig. $4 B$ ). At the same time, the opposite trend was observed in the $\mathrm{vC}^{(-)}$cells: a two-fold decrease in $\mathrm{Chl}$ content took place after $4 \mathrm{~h}$ of post-thaw cultivation followed by a sharp decline in the Chl content till the $7 \mathrm{~d}$ of the cultivation (Fig. 4A,B).

The haematocysts were characterized by the significantly lower initial $\mathrm{Chl}$ content as compared to the vegetative cells (Fig. 4A,B). In the nonfrozen haematocysts as well as thawed $\mathrm{hC}^{(+)}$and $\mathrm{hC}^{(-)}$cells, the Chl content measured immediately after thawing comprised $1.5 \pm 0.2$, $0.8 \pm 0.5$, and $2.2 \pm 0.2 \mathrm{mg} \mathrm{l}^{-1}$, respectively (Fig. 4A), which corresponded to $1.5 \pm 0.2,0.8 \pm 0.5$, and $2.2 \pm 0.2 \mathrm{pg}$ per cell (Fig. $4 B$ ). During $7 \mathrm{~d}$ of the post-thaw cultivation, the increasing Chl content was observed in the haematocyst cultures (Fig. $4 A, B$ ). At the $7^{\text {th }} \mathrm{d}$ of cultivation it reached $4.2 \pm 0.2,5.4 \pm 0.4$, and $3.3 \pm 0.8 \mathrm{pg}$ per cell for the control, $\mathrm{hC}^{(-)}$, and $\mathrm{hC}^{(+)}$cells, respectively (Fig. $4 B$ ).

Photosynthetic activity: Immediately after thawing $(0 \mathrm{~h})$, $\varphi_{\text {Po }}$ values of $\mathrm{vC}^{(+)}$and $\mathrm{vC}^{(-)}$were $0.36 \pm 0.01$ and $0.50 \pm$ 0.02 , respectively (Fig. 4C). A sharp and irreversible decline of $\varphi_{\text {Po }}$ was observed in the $\mathrm{vC}^{(-)}$cells after $4 \mathrm{~h}$ of post-thaw cultivation (Fig. 4C). At $24 \mathrm{~h}$ and $170 \mathrm{~h}, \mathrm{CF}$ parameters of $\mathrm{vC}^{(-)}$were not detected due to profound $\mathrm{Chl}$ 


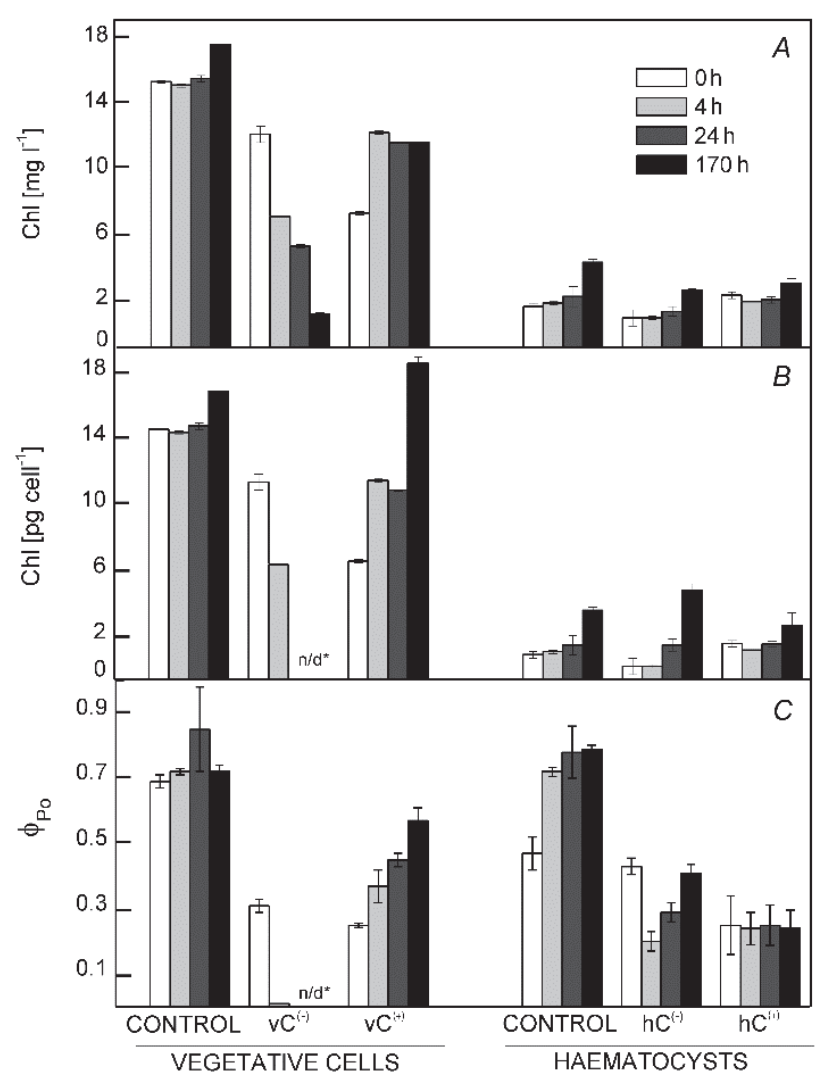

Fig. 4. (A) Total chlorophyll (Chl) content per the littre of the culture and $(B)$ per a cell of vegetative cells and haematocysts of Haematococcus pluvialis BM1 cultivated autotrophically during $7 \mathrm{~d}$ after thawing. $(C){ }_{\varphi \mathrm{Po}}$ of vegetative cells and haematocysts of H. pluvialis BM1 cultivated autotrophically during $7 \mathrm{~d}$ after thawing. Average values of three replicates and their SD are presented in the figures. $\mathrm{vC}^{(+)}, \mathrm{vC}^{(-)}-$vegetative cells with and without cryoprotectants mixture respectively; $\mathrm{hC}^{(+)}, \mathrm{hC}^{(-)}-$ haematocysts with and without cryoprotectants mixture, respectively.

degradation and cell death. By contrast, in the case of $\mathrm{vC}^{(+)}$ cells, $\varphi_{\text {Po }}$ increased gradually and reached $0.57 \pm 0.04$ by after $7 \mathrm{~d}$. Notably, $\varphi_{P_{0}}$ values of nonfrozen vegetative cells were relatively high and did not drop below 0.68 throughout the cultivation time (Fig. 4C). At the initial point of post-thaw cultivation $(0 \mathrm{~h}), \varphi_{\text {Po }}$ of nonfrozen haematocysts was $0.47 \pm 0.06$ and it was expectedly lower than that for vegetative cells (Fig. 4C). Notably, an increase in $\varphi_{\text {Po }}$ values to $0.79 \pm 0.01$ was observed for haematocysts after $7 \mathrm{~d}$ of the cultivation in complete

\section{Discussion}

Freezing-thawing changed dramatically photosynthetic activity and ultrastructure of the vegetative $H$. pluvialis cells. Comparison of the electron micrographs of the vegetative cells suggested that freezing without $\mathrm{CM}$ promoted the formation of numerous damages and loss of
BG-11 medium. In the case of $\mathrm{hC}^{(-)}$cells, a drop in $\varphi_{\mathrm{Po}}$ occurred after $4 \mathrm{~h}$ of the post-thaw cultivation, but after $24 \mathrm{~h}, \varphi_{\text {Po }}$ gradually increased to $0.41 \pm 0.03$ (Fig. $4 C$ ). At the same time, the $\varphi_{\text {Po }}$ values in the $\mathrm{hC}^{(+)}$cells were stable and quite low $(0.25 \pm 0.10)$ during the cultivation period (Fig. 4C). Because $\varphi_{D o}$ is inversely related with $\varphi_{P o}$ (Fig. 1S), an increase in $\varphi_{\text {Po }}$ corresponded to a decline in $\varphi_{\mathrm{P} o}$ and vice versa (Table 1 ).

Additional parameters of the $\mathrm{CF}$ transient curves are presented in Table 1, see also Fig. S1. The $\mathrm{vC}^{(-)}$were characterized by the highest value of $\mathrm{N}$ immediately after thawing (1,782 \pm 954$)$. However, after $4 \mathrm{~h}$ of cultivation, it sharply decreased to $17 \pm 11$. In the nonfrozen cells, this parameter was in the range of 517-896 throughout the cultivation period. The $\mathrm{vC}^{(+)}$cells displayed a low $\mathrm{N}$ immediately after thawing; during $4 \mathrm{~h}$ of cultivation it was $8 \pm 1$ and $40 \pm 39$, respectively. Later, it increased to the values typical for nonfrozen cells $(745 \pm 260$ and $462 \pm$ 148 after 24 and $170 \mathrm{~h}$, respectively). In other cases, this parameter was close to zero $(<25)$.

The parameter $\Psi_{0}$ was relatively high $(0.41-0.55)$ in the nonfrozen cells during the cultivation time. In the $\mathrm{vC}^{(+)}$and $\mathrm{hC}^{(-)}, \Psi_{0}$ increased monotonously from $0.03 \pm 0.03$ to 0.29 \pm 0.02 and $0.15 \pm 0.01$ to $0.41 \pm 0.19$, respectively. In $\mathrm{hC}^{(+)}, \Psi_{0}$ did not change significantly during cultivation time being low with a high dispersion of the values. In the $\mathrm{vC}^{(-)}$cells, this parameter was close to zero. nonfrozen haematocysts and vegetative cells displayed high $\varphi_{\text {Eo }}$ values (in the range of $0.19-0.43$ and $0.28-0.29$, respectively). A mild increasing of $\varphi_{E o}$ from $0.01 \pm 0.01$ to 0.14 \pm 0.00 was observed for $\mathrm{vC}^{(+)}$cells. In other cases, $\varphi_{\text {Eo }}$ was close to zero during all cultivation time.

Retention of astaxanthin accumulation: In order to estimate the ability of the $H$. pluvialis cells to accumulate astaxanthin after freezing-thawing, we compared the astaxanthin content in frozen and nonfrozen cells. The $\mathrm{vC}^{(+)}$and $\mathrm{hC}^{(-)}$cells were inoculated in the glass column photobioreactors. Initially they were cultivated under conditions conductive for vegetative growth, then the cultures were subjected to stress promoting accumulation of astaxanthin (see Materials and methods). The maximal asthaxantin content in $\mathrm{vC}^{(+)}$and $\mathrm{hC}^{(-)}$cells was approximately the same and comprised $3.6 \pm 0.3 \%$ of DM. The astaxanthin content of the nonfrozen cells was $3.8 \pm$ $0.2 \%$ of DM (Fig. $1 B$ ).

the native cell shape indicative of ice crystal formation in the cells. Intracellular water content influences the cell integrity at sub-zero temperatures (Benson 2008). Formation of ice crystals during freezing causes damage of different cell structures and disturbes cell homeostasis. 


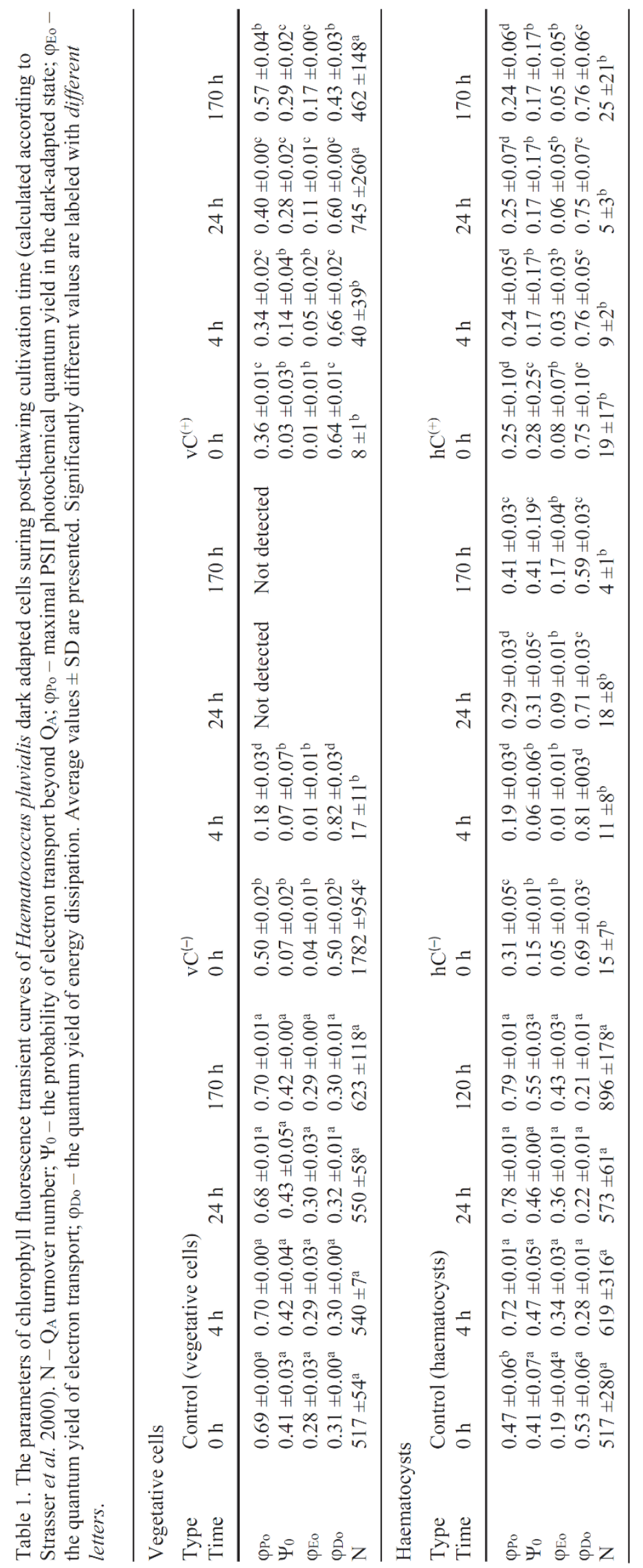


The addition of $\mathrm{CM}$ reduced the risk of mechanical damage by ice crystals most likely via decreasing a water potential of the cell and ice nucleation during water crystallization. Another possible effect can stem from slow down of the diffusion through the cell membranes by increasing of cytoplasm viscosity (Benson 2008). Addition of the CM to the vegetative cells prevented mechanical damage to the cells during freezing and increased cells viability after thawing.

A common mechanism of adaptation to low temperature, which is widespread among cryotolerant microorganisms, is poikilohydry, the ability to decline dramatically water content (Singh and Elster 2007). Based on direct measurements, in $H$. pluvialis, the water content of haematocysts seems to be significantly lower than that in vegetative cells. In addition, the haematocysts normally accumulate abundant lipid bodies as confirmed by TEM of H. pluvialis cells. Thus, the transition of vegetative cells to haematocysts is normally accompanied by a sharp decrease of the area occupied by the membranes of the PSA. The interior of the cytoplasmic lipid globules occupying a significant part of the area on the haematocysts cross-sections consists mainly of triacylglycerines and astaxanthin fatty acid esters forming a strongly hydrophobic compartment (Peled et al. 2011). By contrast, well-developed chloroplasts are enriched in water, especially in its stroma and the intrathylakoid lumen. The decline in the water content of haematocysts is believed to mitigate the risk of mechanical damages and increase viability of the haematocysts even after freezing without CM. Another plausible reason for a lower degree of mechanical damages is the presence of rigid cell wall (Hagen et al. 2008) and lower content of vulnerable membranous structures, e.g., chloroplast thylakoids.

The values of $\varphi_{\text {Po }}$ reflects the potential photochemical efficiency of PSII primary photochemistry. The nonfrozen $H$. pluvialis cells were characterized by high values of $\varphi_{\mathrm{Po}}$ typical for photosynthetically active cells of this microalga (Chekanov et al. 2016, 2017) suggesting that the culturing conditions used in this work were favorable for vegetative growth of $H$. pluvialis. The $\mathrm{vC}^{(-)}$cells were also characterized by relatively high $\varphi_{\text {Po }}$ values immediately after thawing. Thus, these cells possessed an operational PSA. By contrast, the $\varphi_{\text {Po }}$ of the $\mathrm{vC}^{(+)}$were low. Thus, the addition of $\mathrm{CM}$ led to a decrease of $\varphi_{\text {Po }}$ after thawing indicating the increased dissipation of the absorbed light energy as heat. This phenomenon might stem from the effect of DMSO on the structure of photosynthetic membranes and pigment-protein complexes of PSA (Jackson and Mantsch 1991, Notman et al. 2006).

Later, judging from the increase of $\varphi_{\mathrm{P}}$, PSA of the $\mathrm{vC}^{(+)}$recovered. Generally, haematocysts of $H$. pluvialis are characterized by reduction of the PSA and hence by a low photosynthetic activity (Chekanov et al. 2016). Therefore, photosynthetic activity of nonfrozen haematocysts as well as of the $\mathrm{hC}^{(-)}$and $\mathrm{hC}^{(+)}$cells was low at the beginning of cultivation $(0 \mathrm{~h})$. However, under conditions favorable to vegetative growth, the haematocysts return to the state of vegetative cells with well-developed PSA (Chekanov et al. 2016). This process was reflected by the increase in the $\varphi_{\mathrm{P} o}$ of the nonfrozen haematocysts.

It should be noted that $\varphi_{\text {Po }}$ reflects only the potential ability of the cell to utilize the absorbed energy photochemically. To characterize the cell in more details, analysis of additional parameters of primary photochemistry is necessary (Strasser et al. 2000). Particularly, the $\mathrm{N}$ parameter $\left(\mathrm{Q}_{\mathrm{A}}\right.$ turnover number) might reflect potential rate of electron transport at the level of $\mathrm{Q}_{\mathrm{A}}$. Moderately high values of $\mathrm{N}$ were observed in nonfrozen cells. Thus, these cells are capable of more efficient photochemical utilization of the absorbed energy.

A very high turnover number was also observed in the $\mathrm{vC}^{(-)}$cells. It might reflect intensive donation of electrons to ETC by PSII RC. By contrast, in the $\mathrm{vC}^{(+)}$cells and in the frozen haematocysts, this parameter measured immediately after thawing was low indicative of a small electron inflow to the ETC at the level of PSII. On the other hand, nonfrozen $H$. pluvialis cells were characterized by relatively high $\Psi_{0}$ values reflecting a high probability of electron transport beyond $\mathrm{Q}_{\mathrm{A}}$ and hence a high quantum yield of electron transport, $\varphi_{\mathrm{E} o}$.

By contrast, the $\mathrm{vC}^{(-)}$cells were characterized by low values of $\Psi_{0}$ and $\varphi_{\text {Eoo }}$. Taking into account high $\mathrm{N}$ values of $\mathrm{vC}^{(-)}$, it suggests a higher degree of overreduction of the chloroplast electron transport chain, ETC in the $\mathrm{vC}^{(-)}$cells. Thus, in the beginning of post-thaw cultivation $(0 \mathrm{~h})$, the $\mathrm{vC}^{(-)}$cells showed relatively high photosynthetic activity. However, a sharp decline of $\varphi_{\text {Po }}$ was observed in the $\mathrm{vC}^{(-)}$ cultures after $4 \mathrm{~h}$ of cultivation, later these cultures collapsed. This phenomenon might be explained in terms of damage by toxic reactive oxygen species (ROS) generated during impaired functioning of the chloroplast ETC (Asada 2006). Normally, the cell consume light energy and the resulting photosynthates in assimilatory processes. However, imbalance of the electron transport and consumption of the photosynthates in central metabolism imposes a high risk of photodamage. It is conceivable that irradiation of the thawed microalgae cells leads to elevated ROS generation (Fleck et al. 2003) causing cell damage and vegetative cell death. Moreover, the addition of ethylene diamine tetraacetate, which formed complex with $\mathrm{Fe}^{2+}$ promoted Fenton reaction of $\mathrm{OH}$ formation, increased postthaw viability of the Euglena gracillis culture (Fleck et al. 2000). Thus, high PSII activity might be one of the causes of the $\mathrm{vC}^{(-)}$culture death due to photooxidative damage.

By contrast, PSII activity of $\mathrm{vC}^{(+)}$was low. It might prevent the death of these cells at the initial steps of cultivation. Although $\mathrm{vC}^{(+)}$did not reach the values of $\varphi_{\mathrm{P}}$, $\varphi_{\text {Eo }}$, and $\Psi_{0}$ recorded in nonfrozen vegetative cells over the observation time, they demonstrated the trend of recovering of photosynthetic activity.

The low values of $\Psi_{0}$ and $\varphi_{\text {Eo }}$ of the haematocysts are most likely due to the downregulation of photosynthesis. During the cultivation time, the $\Psi_{0}$ and $\varphi_{\text {Eo }}$ values of 
nonfrozen haematocysts increased likely indicating the recovery of their PSA and its return to the active functioning. However, this trend was not observed in the $\mathrm{hC}^{(-)}$and $\mathrm{hC}^{(+)}$cells. It is likely that the freezing stress was too strong for these cells and abolished their fast recovery.

Temporary downregulation of photosynthetic activity in combination with retention of structural integrity of the cells might provide for a complete recovery of PSA at subsequent cultivation. Since $\mathrm{Chl} a$ and $b$ in green microalgae are powerful photosensitizers (Asada 2006), impairment of photoprotective mechanisms on the background of still high $\mathrm{Chl}$ content increases the risk of ROS generation. In view of this, better survival of the $\mathrm{vC}^{(+)}$ cells could also stem from partial extraction of $\mathrm{Chl}$ by DMSO contained in the CM. A concomitant downregulation of the chloroplast ETC functioning mitigates the risk of ROS formation even in the absence of active photoprotective mechanisms functioning normally in the vegetative cells. An additional factor declining the risk of photodamage is the low $\mathrm{Chl}$ content in haematocysts. We believe that these features of haematocysts enhanced their viability after freezing and thawing independently on the $\mathrm{CM}$ addition.

In general, $H$. pluvialis is characterized by a high resistance to freezing-thawing. Reportedly, the tolerance of the microalga to low temperatures is related to a high activity of its ROS-eliminating enzymes (e.g., catalase and superoxide dismutase) as well as to a high content of carotenoids possibly acting as antioxidants (Fleck et al. 2003). However, massive carotenoid accumulation in haematocysts and ROS generation occur in different cell compartments - cytosol and chloroplast, respectively (Boussiba and Vonshak 1991). By contrast, in vegetative cells of the microalga, carotenoids can participate in the prevention of photodamage by ROS scavenging in the photosynthetic membranes and by functioning epoxidation/deepoxidation cycle (Asada 2006, Goltsev et al.

\section{References}

Asada K.: Production and scavenging of reactive oxygen species in chloroplasts and their functions. - Plant Physiol. 141: 391396, 2006.

Benson E.: Cryopreservation of phytodiversity: a critical appraisal of theory \& practice. - Crit. Rev. Plant Sci. 27: 141-219, 2008.

Best B.: Cryoprotectant toxicity: Facts, issues, and questions. - Rejuv. Res. 18: 422-436, 2015.

Bodas K., Brennig C., Diller K., Brand J.: Cryopreservation of blue-green and eukaryotic algae in the culture collection at the University of Texas at Austin. - Cryo-Lett. 16: 267-274, 1995.

Boussiba S., Vonshak A.: Astaxanthin accumulation in the green alga Haematococcus pluvialis. - Plant Cell Physiol. 32: 10771082, 1991.

Boussiba S.: Carotenogenesis in the green alga Haematococcus pluvialis: cellular physiology and stress response. - Physiol. Plantarum 108: 111-117, 2000.
2016, Kalaji et al. 2016). This suggestion is indirectly confirmed by a low expression of ROS-eliminating enzymes in haematocysts (Wang et al. 2004) and efficient operation of the enzymatic mechanisms of ROS protection in vegetative cells.

A common feature of the changes, which occur during the transition of vegetative cells to haematocysts, is switch-over from "active" to "passive" photoprotective mechanisms which does not require continuous energy supply and enzymatic activity (Chekanov et al. 2016). This type of protection is served by optical shielding of the cell by astaxanthin. It is important especially for protection of just thawed and therefore largely metabolically inactive $H$. pluvialis cells. The presence of such protective mechanisms makes the haematocysts of $H$. pluvialis naturally adaptated for long-term cryo-storage even without addition of artificial cryoprotectants.

It should be noted that neither freezing of haematocysts without CM nor vegetative cells with CM caused the lack of the ability to accumulate the high amount of astaxanthin. Thus, it is possible to develop cryopreservation methods of the cultivation of industrial strains of the microalgae without the loss of their biological potential.

Conclusions: A better viability of $H$. pluvialis cells at low temperatures was achieved by preliminary induction of the transition of vegetative cells to haematocysts - resilient cells naturally equipped to cope with the risks of freezing damage. The key factors of the higher freezing tolerance of haematocysts were: (1) low water content, (2) rigid cell walls, (3) smaller membrane structures vulnerable to damage, (4) downregulation of photosynthesis, and 5) low $\mathrm{Chl}$ content. Whereas survival of the vegetative cells of $H$. pluvialis after freezing and thawing depended on the presence of cryoprotectants, haematocysts do not require the addition of cryoprotectants to cope with the freezing damage.

Brand J.J., Diller K.R.: Application and theory of algal cryopreservation. - Nova Hedwigia 79: 175-189, 2004.

Bui T.V., Ross I.L., Jakob G., Hankamer B.: Impact of procedural steps and cryopreservation agents in the cryopreservation of chlorophyte microalgae. - PLoS ONE 8: e78668, 2013.

Cañavate J.P., Lubian L M.: Relationship between cooling rates, cryoprotectant concentrations and salinities in the cryopreservation of marine microalgae. - Mar. Biol. 124: 325-334, 1995.

Cañavate J., Lubian L.: Tolerance of six marine microalgae to the cryoprotectants dimethyl sulfoxide and methanol. - J. Phycol. 30: 559-565, 1994.

Chekanov K.A., Solovchenko A.E.: Possibilities and limitations of non-destructive monitoring of the unicellular green microalgae (Chlorophyta) in the course of balanced growth. - Russ. J. Plant Physl+ 62: 270-278, 2015.

Chekanov K., Lobakova E., Selyakh I. et al.: Accumulation of astaxanthin by a new Haematococcus pluvialis strain BM1 
from the White Sea coastal rocks (Russia). - Mar. Drugs. 12: 4504-4520, 2014.

Chekanov K., Lukyanov A., Boussiba S. et al.: Modulation of photosynthetic activity and photoprotection in Haematococcus pluvialis cells during their conversion into haematocysts and back. - Photosynth. Res. 128: 313-323, 2016.

Chekanov K., Schastnaya E., Solovchenko A., Lobakova E.: Effects of $\mathrm{CO}_{2}$ enrichment on primary photochemistry, growth and astaxanthin accumulation in the chlorophyte Haematococcus pluvialis. - J. Photoch. Photobio. B 171: 58-66, 2017.

Day J.G., Watanabe M.M., Morris G.J. et al.: Long-term viability of preserved eukaryotic algae. - J. Appl. Phycol. 9: 121-127, 1997.

Day J., Brand J.: Cryopreservation methods for maintaining cultures. - In: Andersen R.A. (ed.): Algal Culturing Techniques. Pp. 165-187. Academic Press, New York 2005.

Day J.G., DeVille M.M.: Cryopreservation of Algae. Pp. 81-89. Humana Press Inc., Totowa 1995.

Fleck R.A., Benson E.E., Bremner D.H., Day J.G.: Studies of free radical-mediated cryoinjury in the unicellular green alga Euglena gracilis using a non-destructive hydroxyl radical assay: a novel approach for developing protistan cryopreservation strategies. - Free Radic Res. 32: 157-170, 2000.

Fleck R., Benson E., Bremner D., Day J.: A comparative study of antioxidant protection in cryopreserved unicellular algae Euglena gracilis and Haematococcus pluvialis. - Cryo-Lett. 24: 213-228, 2003.

Goltsev V., Kalaji M.H., Paunova M. et al.: Using a variable chlorophyll fluorescence for evaluation of physiological state photosynthetic apparatus plants. - Russ. J. Plant Physl+ 63: 128, 2016.

Hagen C., Siegmund S., Braune W.: Ultrastructural and chemical changes in the cell wall of Haematococcus pluvialis (Vovocales, Chlorophyta) during aplanospore formation. Eur. J. Phycol. 37: 217-226, 2008.

Han D., Li Y., Hu Q.: Astaxanthin in microalgae: pathways, functions and biotechnological implications. - Algae 28: 131147, 2013

Harding K., Muller J., Lorenz M. et al.: Deployment of the encapsulation-dehydration protocol to cryopreserve microalgae held at the Sammlung von Algenkulturen, Universität Gottingen, Germany. - Cryo-Lett. 29: 15-20, 2008.

Jackson M., Mantsch H.H.: Beware of proteins in DMSO. - BBA-Protein Struct. M. 1078: 231-235, 1991.

Kalaji H.M., Schansker G., Brestic M. et al.: Frequently asked questions about chlorophyll fluorescence, the sequel. Photosynth. Res. 132: 13-66, 2016.

Klochkova T.A., Kwak M.S., Han J.W. et al.: Cold-tolerant strain of Haematococcus pluvialis (Haematococcaceae, Chlorophyta) from Blomstrandhalvøya (Svalbard). - Algae 28: 185-192, 2013.
Morris G.J.: Cryopreservation of 250 strains of Chlorococcales by the method of two-step cooling. - Brit. Phycol. J. 13: 15-24, 1978.

Morschett H., Reich,S., Wiechert W., Oldiges M.: Simplified cryopreservation of the microalga Chlorella vulgaris integrating a novel concept for cell viability estimation. - Eng. Life Sci. 16: 36-44, 2016.

Notman R., Noro M., O'Malley B., Anwar J.: Molecular basis for dimethylsulfoxide (DMSO) action on lipid membranes. - J. Am. Chem. Soc. 128: 13982-13983, 2006.

Pal D., Khozin-Goldberg I., Cohen Z., Boussiba S.: The effect of light, salinity, and nitrogen availability on lipid production by Nannochloropsis sp. - J. Appl. Microbiol. Biotechnol. 90: 1429-1441, 2011.

Peled E., Leu S., Zarka A. et al.: Isolation of a novel oil globule protein from the green alga Haematococcus pluvialis (Chlorophyceae). - Lipids 46: 851-861, 2011.

Piasecki B.P., Diller K.R., Brand J.J.: Cryopreservation of Chlamydomonas reinhardtii: a cause of low viability at high cell density. - Cryobiology 58: 103-109, 2009.

Pouneva I.: Evaluation of algal culture viability and physiological state by fluorescent microscopic methods. - Bulg. J. Plant Physiol. 23: 67-76, 1997.

Saadaoui I., Al Emadi M., Bounnit T. et al.: Cryopreservation of microalgae from desert environments of Qatar. - J. Appl. Phycol. 28: 2233-2240, 2016.

Singh S.M., Elster J.: Cyanobacteria in Antarctic lake environments. - In.: Seckbach J.: Algae and Cyanobacteria in Extreme Environments. Pp. 303-320. Springer, Dordrecht 2007.

Solovchenko A.E.: Recent breakthroughs in the biology of astaxanthin accumulation by microalgal cell. - Photosynth. Res. 125: 437-449, 2015.

Solovchenko A., Merzlyak M.N., Khozin-Goldberg I. et al.: Coordinated carotenoid and lipid syntheses induced in Parietochloris incisa (Chlorophyta, Trebouxiophyceae) mutant deficient in $\Delta 5$ desaturase by nitrogen starvation and high light. - J. Phycol. 46: 763-772, 2010

Stanier R.Y., Kunisawa R., Mandel M., Cohen-Bazire G.: Purification and properties of unicellular blue-green algae (order Chroococcales). - Bacteriol. Rev. 35: 171-205, 1971.

Strasser R.J., Srivastava A., Tsimilli-Michael M.: The fluorescence transient as a tool to characterize and screen photosynthetic samples. - In: Yunus M, Pathre U, Mohanty P. (ed.): Probing Photosynthesis: Mechanisms, Regulation and Adaptation. Pp. 445-483. Taylor \& Francis, London 2000.

Wang S.B., Chen F., Sommerfeld M., Hu Q.: Proteomic analysis of molecular response to oxidative stress by the green alga Haematococcus pluvialis (Chlorophyceae). - Planta 220: 1729, 2004 